\title{
Autopsy-Based Study of Abdominal Traffic Trauma Death after Emergency Room Arrival
}

\author{
Satoshi Furukawa*, Satomu Morita, Katsuji Nishi, Masahito Hitosugi \\ Department of Legal Medicine, Shiga University of Medical Science, Shiga, Japan \\ Email: ${ }^{*}$ 31041220@belle.shiga-med.ac.jp
}

Received 4 May 2015; accepted 20 July 2015; published 23 July 2015

Copyright (C) 2015 by authors and Scientific Research Publishing Inc.

This work is licensed under the Creative Commons Attribution International License (CC BY). http://creativecommons.org/licenses/by/4.0/

c) (i) Open Access

\begin{abstract}
We experienced the autopsy cases that the deceased was alive in emergency room on arrival. Bleeding is the leading cause of preventable death after injury. This retrospective study aimed to characterize opportunities for performance improvements identified in patients who died from traffic trauma and were considered by the quality improvement of education system. We focused the abdominal traffic trauma injury. An autopsy-based cross-sectional study was conducted. A purposive sampling technique was applied to select the study sample of 41 post-mortems of road traffic accident. 16 patients $(39.0 \%)$ were abdominal trauma injury. The mean period of survival after meeting with accident was 13.5 hours, and compared abdominal trauma death was 27.4 hours longer. In road traffic accidents, the most injured abdominal organs were the liver followed by mesentery. We thought that delayed treatment was associated with immediate diagnostic imaging, and so expected to expand trauma management examination.
\end{abstract}

\section{Keywords}

Abdominal Traffic Trauma, Preventable Death, Autopsy

\section{Introduction}

The abdomen is the common region of the body that is injured in civilian trauma. Blunt abdominal trauma is one of the leading causes of the mortality among trauma victims [1]. Haemorrhage is the leading cause of preventable death after trauma [2]. The management of potentially fatal traumatic haemorrhage is a complex and dynamic multidisciplinary process. Substantial international evidence shows that trauma outcomes are optimized

${ }^{*}$ Corresponding author.

How to cite this paper: Furukawa, S., Morita, S., Nishi, K. and Hitosugi, M. (2015) Autopsy-Based Study of Abdominal Traffic Trauma Death after Emergency Room Arrival. Forensic Medicine and Anatomy Research, 3, 77-81.

http://dx.doi.org/10.4236/fmar.2015.33013 
by working within inclusive trauma systems with effective quality improvements [3] [4]. The tri-model distribution of trauma deaths was first described in 1983 [5]. As a function of elapsed time after injury, deaths from traumatic injury are classified as generally falling into one of three categories: immediate, early, and late. Immediate deaths are those that occur $<1 \mathrm{~h}$ after injury, making up $\sim 50 \%$ of the total; early deaths occur within the first few hours after injury and account for 30\%; and late deaths occur days to weeks after injury and are 20\% of all trauma deaths. Immediate deaths are largely due to neurologic injury (brain, brain stem, spinal cord) or laceration of the heart or major vessels and classified as not preventable.

Early deaths are largely due to severe blood loss from the head, respiratory system, and abdominal organs. These deaths are largely treatable and therefore possibly preventable. Finally, most late deaths are due to infection and multi organ failure. Reducing the number of injury-related deaths during each period largely relies upon expedient and optimal medical care [6]-[8]. Trauma care in Japan in the early 2000s was not satisfactory; a national survey reported in 2002 that death might have been prevented in approximately 38\% of patients with trauma who arrived at the hospital with any vital signs [9]. We conduct an autopsy-based cross-sectional study and analyze the epidemiology and pattern of fatal abdominal injuries in road traffic accidents.

\section{Materials and Method}

An autopsy-based, cross-sectional study conducted in correlation with the relevant clinical records. A purposive sampling technique was applied to select the study sample of 41 post-mortems autopsies, which were alert at the emergency room on arrival, between April 1999 and March 2014 (for 15 years) of traffic trauma death to medico-legal autopsy at the department of Forensic Medicine, Shiga University of Medical Science, Japan. The data were compiled with a focus on the analysis of injuries in the abdominal region with special reference to the nature of the wound and organs most commonly affected in traffic accidents and epidemiological factors in relation to victims and vehicles. Details availably included age, gender, time and date of injury, time and date of death, and cause to death. The mechanism of injury and cause of death were determined by autopsy.

\section{Results}

16 patients (39.0\%), mean age 57.8 years (18 - 91 years), were abdominal trauma injury. Data were collected on patient demographics, mechanism of injury, abbreviated injury scale (AIS), and injury severity score (ISS). Max AIS was five and all patients had an ISS > 25 (mean ISS was 38.3.). Of these patients, 11 patients (68.8\%) were male and car drivers were seven, followed by pedestrians five, and two-wheelers (motor cyclist scooterist, bicycle etc.) four. The mean period of survival after meet with accident was 13.5 hours (30 minutes-112 hours). The nine victims survived more than 3 hours after the traffic accident. We determined the direct cause of death was abdominal trauma of six cases by autopsy. The breakdown of cause of death was fatal traumatic haemorrhage (5 cases) and peritonitis ( 1 case). Only six cases, the mean period of survival after meet with accident was 27.4 hours longer. In this study, abdominal injured were liver (six cases), mesentery (four cases), gastrointestinal tract, diaphragm (each three cases), spleen, kidney, and abdominal aorta (each one case) (Table 1 and Table 2) (Figure 1 and Figure 2).

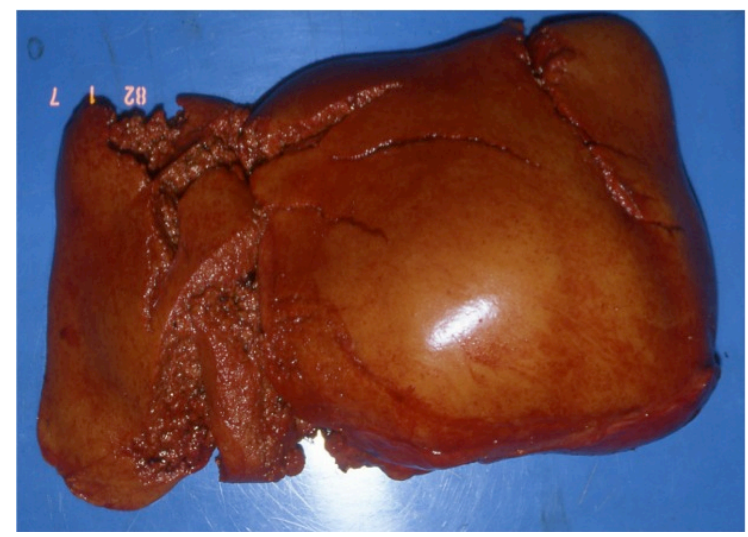

Figure 1. The superficial contusion in the liver. (Case 10). 


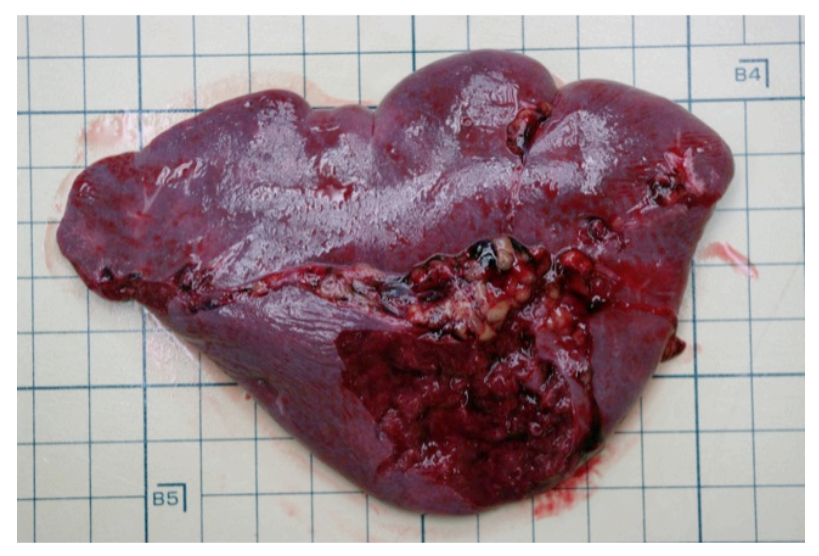

Figure 2. The ventral injury in the spleen (Case 16).

Table 1. Demographic and injury characteristics of abdominal trauma injury (16 cases).

\begin{tabular}{|c|c|c|c|c|c|c|c|}
\hline 1 & 71 & M & 4 & 25 & 34 & Lt. renal injury & car \\
\hline 2 & 57 & M & 5 & 43 & 0.5 & pancreas rupture, spleen rupture, mesenteric injury & car \\
\hline 3 & 20 & M & 5 & 45 & 22 & ascending colon rupture, diaphragmatic injury & motor bicycle \\
\hline 4 & 69 & M & 5 & 30 & 7 & pelvic fracture, diaphragmatic injury & bicycle \\
\hline 5 & 77 & $\mathrm{~F}$ & 5 & 50 & 2 & heart rupture, pulmonary contusion, liver contusion & pedestrian \\
\hline 6 & 58 & M & 5 & 38 & 1.5 & thoracic aortic rupture, mesenteric injury & car \\
\hline 7 & 65 & $\mathrm{~F}$ & 4 & 34 & 112 & diaphragmatic rupture & motor bicycle \\
\hline 8 & 49 & M & 5 & 33 & 2.5 & liver contusion, pancreas rupture & car \\
\hline 9 & 75 & M & 5 & 29 & 3 & abdominal aortic rupture, subarachnoid hemorrhage & pedestrian \\
\hline 10 & 65 & M & 4 & 29 & 11 & liver contusion, mesenteric injury & pedestrian \\
\hline 11 & 59 & M & 5 & 38 & 1.5 & liver contusion & pedestrian \\
\hline 12 & 80 & M & 4 & 36 & 6.5 & mediastinal hematoma, multipke rib fracture, mesenteric injury & car \\
\hline 13 & 37 & $\mathrm{~F}$ & 5 & 54 & 2 & liver rupture, brain contusion & car \\
\hline 14 & 18 & $\mathrm{~F}$ & 5 & 45 & 4 & lung injury, splenic injury & car \\
\hline 15 & 34 & M & 5 & 50 & 4 & liver contusion, splenic injury & motor bicycle \\
\hline 16 & 91 & $\mathrm{~F}$ & 5 & 33 & 2 & abdominal aortic rupture & pedestrian \\
\hline
\end{tabular}

Table 2. The breakdown of abdominal trauma death (6 cases).

\begin{tabular}{|c|c|c|c|c|c|c|}
\hline & age & gender & Max AIS & ISS & Time from Injury to Death & The direct cause of death \\
\hline Case 1 & 71 & M & 4 & 25 & 34 & hemorrhagic shock \\
\hline Case 7 & 65 & $\mathrm{~F}$ & 4 & 34 & 112 & peritonitis \\
\hline Case 8 & 49 & M & 5 & 33 & 2.5 & hemorrhagic shock \\
\hline Case 9 & 75 & M & 5 & 29 & 3 & hemorrhagic shock \\
\hline Case 10 & 65 & M & 4 & 29 & 11 & hemorrhagic shock \\
\hline Case 16 & 91 & $\mathrm{~F}$ & 5 & 33 & 2 & hemorrhagic shock \\
\hline
\end{tabular}

AIS: Abbreviated Injury Scale; ISS: Injury Severity Score; Time from Injury to Death (hr). 


\section{Discussion}

In 1980, the American College of Surgeons Committee on Trauma established an educational program for initial trauma care, the ATLS program [10]. Several improvements have been reported in the quality of trauma care and in mortality rates [11]-[13]. To help eliminate preventable deaths from trauma and to improve trauma care in Japan, in 2002 the Joint Committee of the Japanese Association for the Surgery of Trauma and Japanese Association for Acute Medicine corporately developed a standardized trauma care protocol, named the Japan Advanced Trauma Evaluation and Care (JATEC) [14] [15]. The JATEC is a 2-day off-the-job training course in initial trauma management that consists of a primary survey (i.e., physiological, ABCDE approach) and a secondary survey (i.e., history taking and anatomical, systemic approach) and as such it is similar to ATLS [16].

This study was a retrospective observational autopsy-based study. Trauma severity was generally as indicated by significantly higher ISS. The period of survival after meet with accident was tendency of long in the abdominal trauma death. A faulty ultrasound machine might predispose to a failure to perform an early focused assessment with sonography for trauma (FAST) scan and therefore to diagnose intra-abdominal bleeding. FAST is convenient because of capable use in the emergency room.

Computed tomography (CT) scanning is increasingly and aggressively used in trauma care. However, the attitude of immediate diagnosis attributed to CT and radiology might be delay in treatment. Acting as coordinated trauma response is to improve the timing and quality of the emergency response through the appropriate use of acute interventions, such as fluid replacement, endotracheal intubation, transcatheter arterial embolization (TAE), and emergency surgery [10] [11]. Problems with judgment of the emergency response are associated with remediable failures in care. The decision critical to patients with significant bleeding is between immediate intervention and further investigation. Some studies of deaths after trauma have found that 5 - 35 per cent are "preventable” or "potentially preventable”, and errors are found in many aspects of care [17]-[23].

\section{Conclusion}

We examined autopsy-based study. In abdominal traffic trauma death, the mean period of survival after meeting with accident was longer. We thought that the cause of delay is the appropriate judgment through the use of acute interventions. We needed to expand the trauma examination training education to avoid preventable trauma death.

\section{References}

[1] King, Y., David, T., Onoja, F. and Inunduh, P. (2005) Blunt Injuries to the Abdomen in Makurdi, Benue State: Nigeria. Nigerian Journal of Surgical Research, 7, 173-175.

[2] Pfeifer, R., Tarkin, I.S., Rocos, B. and Pape, H.C. (2009) Patterns of Mortality and Causes of Death in Polytrauma Patients-Has Anything Changed? Injury, 40, 907-911. http://dx.doi.org/10.1016/j.injury.2009.05.006

[3] Utter, G.H., Maier, R.V., Rivara, F.P., Mock, C.N., Jurkovich, G.J. and Nathens, A.B. (2006) Inclusive Trauma Systems: Do They Improve Triage or Outcomes of the Severely Injured? Journal of Trauma-Injury Infection \& Critical Care, 60, 529-537. http://dx.doi.org/10.1097/01.ta.0000204022.36214.9e

[4] Davenport, R.A., Tai, N., West, A., Bouamra, O., Aylwin, C., Woodford, M., et al. (2010) A Major Trauma Centre Is a Specialty Hospital Not a Hospital of Specialties. British Journal of Surgery, 97, 109-117. http://dx.doi.org/10.1002/bjs.6806

[5] Trunkey, D.D. (1983) Trauma. Accidental and Intentional Injuries Account for More Years of Life Lost in the U.S. than Cancer and Heart Disease. Among the Prescribed Remedies Are Improved Preventive Efforts, Speedier Surgery and Further Research. Scientific American, 249, 28-35. http://dx.doi.org/10.1038/scientificamerican0883-28

[6] Meislin, H., Criss, E., Judkins, D., Berger, R., Conroy, C., et al. (1997) Fatal Trauma: The Model Distribution of Time to Death Is a Function of Patients' Demographics and Regional Resources. Journal of Trauma-Injury Infection \& Critical Care, 43, 433-440. http://dx.doi.org/10.1097/00005373-199709000-00008

[7] Sauaia, A., Moor, F.A., Moore, E.E., Moser, K.S., Brennan, R., et al. (1995) Epidemiology of Trauma Deaths: A Reassessment. Journal of Trauma-Injury Infection \& Critical Care, 38, 185-193.

[8] Demetriades, D., Kimbrell, B., Salim, A., Velmahos, G., Rhee, P., et al. (2005) Trauma Deaths in a Mature Urban Trauma System: Is "Trimodal” Distribution a Valid Concept? Journal of the American College of Surgeons, 201, 343-348. http://dx.doi.org/10.1016/j.jamcollsurg.2005.05.003

[9] Otomo, Y., Hemmi, H., Honma, M., et al. (2002) Quality of Trauma Care at Each Hospital Should Be Evaluated for 
Deciding the Receiving Hospital. Journal of the Japanese Association for the Surgery of Trauma, 16, 319-323. (In Japanese)

[10] Johon, F. (2011) History of the ATLS Program.

[11] Colicott, P.E. and Hughes, I. (1980) Training in Advanced Trauma Life Support. JAMA, 243, 1156-1159.

[12] Ali, J., Adam, R., Butler, A.K., Chang, H., Howard, M., et al. (1993) Trauma Outcome Improves Following the Advanced Trauma Life Support Program in a Developing Country. Journal of Trauma-Injury Infection \& Critical Care, 34, 890-898.

[13] Adam, R., Stedman, M., Winn, J., Howard, M., Williams, J.I., et al. (1994) Improving Trauma Care in Trinidad and Tobago. West Indian Medical Journal, 43, 36-38.

[14] Mashiko, M. (2005) Trauma Systems in Japan: History, Present Status, and Future Perspectives. Journal of Nippon Medical School, 72, 194-202.

[15] Developing Committee on the Course of Trauma Care Training of the Japan Association for the Surgery of Trauma (2012) Guideline for Initial Trauma Care. Japan Advanced Trauma 28. Evaluation and Care. 4th Edition, Herusu Shuppan Company, Tokyo. (In Japanese)

[16] Akio, K. (2005) JATEC Initial Management of Trauma. Jpn J Pediatr Surg, 37, 134-140.

[17] Cayten, C.G., Stahl, W.M., Agarwal, N. and Murphy, J.G. (1991) Analyses of Preventable Deaths by Mechanism of Injury among 13,500 Trauma Admissions. Annals of Surgery, 214, 510-520. http://dx.doi.org/10.1097/00000658-199110000-00015

[18] Davis, J.W., Hoyt, D.B., McArdle, M.S., Mackersie, R.C., Shackford, S.R. and Eastman, A.B. (1991) The Significance of Critical Care Errors in Causing Preventable Death in Trauma Patients in a Trauma System. Journal of Trauma-Injury Infection \& Critical Care, 31, 813-818. http://dx.doi.org/10.1097/00005373-199106000-00012

[19] Campbell, S., Watkins, G. and Kreis, D. (1989) Preventable Deaths in a Self-Designated Trauma System. American Surgeon, 55, 478-480.

[20] Esposito, T.J., Sanddal, T.L., Reynolds, S.A. and Sanddal, N.D. (2003) Effect of a Voluntary Trauma System on Preventable Death and Inappropriate Care in a Rural State. Journal of Trauma-Injury Infection \& Critical Care, 54, 663669. http://dx.doi.org/10.1097/01.TA.0000058124.78958.6B

[21] Davis, J.W., Hoyt, D.B., McArdle, M.S., Mackersie, R.C., Eastman, A.B., Virgilio, R.W., et al. (1992) An analysis of errors causing morbidity and mortality in a trauma system: a guide for quality improvement. Journal of Trauma-Injury Infection \& Critical Care, 32, 660-665. http://dx.doi.org/10.1097/00005373-199205000-00020

[22] Ivatury, R.R., Guilford, K., Malhotra, A.K., Duane, T., Aboutanos, M. and Martin, N. (2008) Patient Safety in Trauma: Maximal Impact Management Errors at a Level I Trauma Center. Journal of Trauma-Injury Infection \& Critical Care, 64, 265-270. http://dx.doi.org/10.1097/TA.0b013e318163359d

[23] Esposito, T.J., Sanddal, N.D., Hansen, J.D. and Reynolds, S. (1995) Analysis of Preventable Trauma Deaths and Inappropriate Trauma Care in a Rural State. Journal of Trauma-Injury Infection \& Critical Care, 39, 955-962. http://dx.doi.org/10.1097/00005373-199511000-00022 